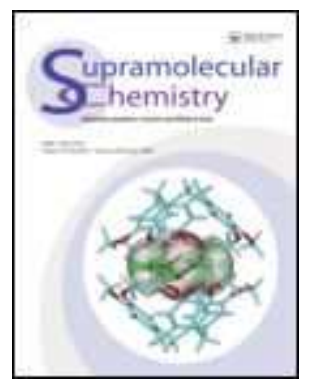

\title{
Cyclophanes Or Cyclodextrins: What Is The Best Host For Aromatic Volatile Organic Compounds?
}

\begin{tabular}{|r|l|}
\hline Journal: & Supramolecular Chemistry \\
\hline Manuscript ID: & GSCH-2007-0044.R1 \\
\hline Manuscript Type: & Full Paper \\
\hline Author: & $13-$ Mar-2007 \\
\hline Complete List of Authors: & $\begin{array}{l}\text { Ionut Dron, Paul; LSOE } \\
\text { Fourmentin, Sophie; LSOE, MREI } \\
\text { Cazier, Francine; LSOE } \\
\text { Landy, David; LSOE } \\
\text { Surpateanu, Gheorghe; LSOE }\end{array}$ \\
\hline Keywords: & $\begin{array}{l}\text { Cyclophanes, Cyclodextrins, Inclusion compounds, Static } \\
\text { headspace, Molecular modelling }\end{array}$ \\
\hline & \\
\hline $\begin{array}{l}\text { Note: The following files were submitted by the author for peer review, but cannot be converted } \\
\text { to PDF. You must view these files (e.g. movies) online. }\end{array}$ \\
\hline Figure1.cdx
\end{tabular}

\section{今 ScholarONE" \\ Manuscript Central}


Cyclophanes Or Cyclodextrins: What Is The Best Host For Aromatic Volatile Organic Compounds?

Paul Ionut Dron, Sophie Fourmentin ${ }^{1}$, Francine Cazier, David Landy and Gheorghe Surpateanu

Laboratoire de Synthèse Organique et Environnement (EA2599), Université du Littoral Côte d'Opale, 145 Avenue Maurice Schumann, 59140 Dunkerque, France.

\begin{abstract}
The first results of the complexing ability of cyclobis(paraquat- $p$-phenylene) as supramolecular host with different aromatic volatile organic compounds are presented. The formation constants of cyclobis(paraquat-p-phenylene) with toluene and halogenobenzenes were determinated in aqueous solution by static headspace associated with gas chromatography and compared with the ones obtained by cyclodextrins. The data indicated the formation of 1:1 inclusion compounds in both cases. The results underlined a greater complexation ability for cyclobis(paraquat- $p$-phenylene) which was confirmed by a theoretical study.
\end{abstract}

Keywords: Cyclophanes, Cyclodextrins, Inclusion compounds, Static headspace, Molecular modelling

\title{
Introduction
}

${ }^{1}$ Corresponding author email: lamotte@univ-littoral.fr 
Cyclobis(paraquat-p-phenylene) $\left(\mathrm{CBPQT}^{4+}\right)$ (Figure 1) and its inclusion complexes have drawn much attention because of their many interesting properties and applications especially in the design of nanoscale molecular devices [1,2]. This cyclophane can be employed as a binding probe for studies in molecular recognition. Our interest lies in volatile organic compounds (VOCs) recognition by supramolecular hosts like modified cyclodextrins (CDs) (Figure 1) or cyclophanes [3,4]. Indeed, the internal cavity of $\mathrm{CBPQT}^{4+}$ has a shape and hydrophobicity that make it a selective inclusion host for aromatic residues $[5,6]$.

\section{Insert Figure 1}

Association of $\mathrm{CBPQT}^{4+}$ with an electron rich aromatic guest produces a colored, charge-transfer complex. Binding constants are then usually determined by monitoring the appearance of this complex using standard spectrometric methods. These methods are not appropriate in the case of VOCs as guest because of the low solubility and the high volatility of these compounds. We have recently developed a method based on static headspace gas chromatography (HSGC) to study the inclusion complex formed between CDs and VOCs [7]. This method has been applied to the determination of the formation constant of the inclusion complexes formed between $\mathrm{CBPQT}^{4+}$ tetrachloride salt, $\alpha$-cyclodextrin $(\alpha-C D), \quad \beta$-cyclodextrin $(\beta-C D)$ and randomly-methylated- $\beta$ cyclodextrin (RAMEB) with toluene and halogenobenzenes in water.

\section{Results and discussions}


In order to evaluate the inclusion ability of the supramolecular hosts, we used a static headspace method. Such a method is based on the variation of the peak area of the VOC observed upon addition of each host in a solution containing the VOC.

The stability constants for the inclusion of VOCs with $\mathrm{CBPQT}^{4+}, \alpha-\mathrm{CD}, \beta-\mathrm{CD}$ and RAMEB in aqueous solution were determined at $30^{\circ} \mathrm{C}$ with four host concentrations (35mM, 20mM, 10mM and 5mM for RAMEB; $7 \mathrm{mM}, 4 \mathrm{Mm}, 2 \mathrm{mM}$ and $1 \mathrm{mM}$ for $\alpha-\mathrm{CD}$ and $\beta-\mathrm{CD} ; 0.3 \mathrm{mM}, 0.2 \mathrm{mM}, 0.1 \mathrm{mM}$ and $0.03 \mathrm{mM}$ for $\mathrm{CBPQT}^{4+}$ ). The effect of an increased concentration of $\mathrm{CBPQT}^{4+}$ on the chromatographic peak of toluene is shown in Figure 2.

\section{Insert Figure 2}

The obtained variations are in good agreement with the 1:1 host/guest ratio, as could be expected from analogous results for other substituted benzene derivatives for cyclophanes [8,9] or cyclodextrins [10-13]. The experimental data obtained for iodobenzene and $\mathrm{CBPQT}^{4+}$ are given in Figure 3 with the theoretical curve for a 1:1 complex with a formation constant of $9459 \mathrm{M}^{-1}$. As one can see, the experimental points fit well with the theoretical curve.

\section{Insert Figure 3}

The formation constants are calculated by an algorithmic procedure [14] and are reported in Table 1 in comparison with literature data (in bracket) [11-13].

\section{Insert Table 1}


There are few references in literature in which HSGC is used for determining stability constants of different compounds with CDs [15-20] and especially for VOCs $[13,21,22]$.

The obtained formation constants are in good agreement with the corresponding ones found in literature for CDs [11-13], while, in the case of $\mathrm{CBPQT}^{4+}$, the values are in the same order of magnitude than for other aromatic guests in aqueous media $[8,9]$. The formation constants obtained with $\mathrm{CBPQT}^{4+}$ are 10 to 100 -fold stronger than for CDs, which demonstrates a greater complexation ability of the cyclophane.

In addition, if one plots the logarithm of the formation constant $\left(\log K_{f}\right)$ as a function of the molar refractivity (MR) of the substituent (Figure 4), a good linear relationship is obtained for both $\mathrm{CBPQT}^{4+}$ and $\beta-\mathrm{CD}$. This linear variation with the size of the substituent shows that Van der Waals interactions are important for the two supramolecular hosts. In addition, it has to be underlined that nearly identical slopes are obtained for the two hosts, whereas a greater intercept is observed for $\mathrm{CBPQT}^{4+}$. This leads to think that the greater complexation ability of the cyclophane is a consequence of a better encapsulation of the phenyl ring.

\section{Insert Figure 4}

In order to get better insights into the mechanisms of complexation, we have also realised a comparative docking study of iodobenzene into $\mathrm{CBPQT}^{4+}$ and $\beta-\mathrm{CD}$. The initial $\mathrm{CBPQT}^{4+}$ structure was in agreement with literature data (geometrical parameters 
strictly equal to already published PM3 results) [23-24]. The optimal docked structures are illustrated in Figure 5.

\section{Insert Figure 5}

It can be seen that a very close proximity exists between iodobenzene and CBPQT ${ }^{4+}$, leading to a greater stabilisation by Van der Waals forces than for $\beta$-CD inclusion compound. Indeed, a value of $-15.7 \mathrm{kcal} / \mathrm{mol}$ is obtained in the case of $\mathrm{CBPQT}^{4+}$, against $-10.6 \mathrm{kcal} / \mathrm{mol}$ for $\beta-\mathrm{CD}$. Moreover, the existence of charges on the cyclophane structure implies greater electrostatic interactions with the guest than those taking place with $\beta$-CD $(-8.7 \mathrm{kcal} / \mathrm{mol}$ against $-0.8 \mathrm{kcal} / \mathrm{mol})$. Thus, experimental and theoretical data suggest that both steric complementarity and charge-transfert mechanisms are operating inside the cyclophane complex, whereas CD complex is mainly influenced by Van der Waals interactions. As a consequence, the total stabilisation energy is largely in favour of $\mathrm{CBPQT}^{4+}(-24.4 \mathrm{kcal} / \mathrm{mol}$ against $-11.6 \mathrm{kcal} / \mathrm{mol})$, which is in good qualitative agreement with the determined formation constants.

\section{Materials and methods}

a) Chemicals

Toluene and halogenobenzenes (Aldrich) were all of analytical reagent grade and were used as received. $\alpha-C D, \beta-C D$ and RAMEB were purchased from Wacker Chimie S.A. (Lyon). Cyclobis(paraquat- $p$-phenylene) was synthesised in our laboratory as described [6]. Tetrachloride salt of $\mathrm{CBPQT}^{4+}$ was used because of its greater solubility $(\sim 2 \mathrm{mM})$ 
compared with tetrakis(hexafluorophosphate) salt $(\sim 0.01 \mathrm{mM})$. Deionised water was used throughout this work.

b) Static headspace

Headspace sampling is employed with gas chromatography (GC) in numerous fields and with a variety of applications $[25,26]$. A headspace sample is in principle a gas sample which has been previously in contact with a liquid or solid sample from which volatile compounds were released into the gas with subsequent analysis by gas chromatography. Headspace gas chromatography is therefore a technique of gas extraction and can be carried out comparable to a solvent extraction as a one-step extraction (static or equilibrium headspace) or as a continuous extraction (dynamic headspace) [27]. Measurements were conducted with a Agilent headspace autosampler. Sample solutions of $5 \mathrm{~mL}$ containing various concentrations of pollutant (10-100 ppm) were introduced into $10 \mathrm{~mL}$ headspace vials and sealed using silicone septa and aluminium foil. The vials were then thermostated at $30 \pm 0.1^{\circ} \mathrm{C}$. After the equilibrium was established (30 min), $1 \mathrm{~mL}$ of vapor from the above solution was drawn out from the vial using a gas-tight syringe and injected directly in the chromatographic column via a transfer line. This sample was then analyzed by gas chromatography (Perkin Elmer Autosystem XL) equipped with a flame-ionization detector using a DB624 column. The GC settings were programmed as follows: detector temperature, $280^{\circ} \mathrm{C}$; column temperature, $120^{\circ} \mathrm{C}$ during $8 \mathrm{~min}$.

Full equilibrium of the chemical solute between liquid and gas phases is required. For the chemicals tested, the equilibrium time was $30 \mathrm{~min}$. Linear response of the GC detector to the chemical concentration range tested is another requirement for the 
successful application of the method. For all compounds, we verify that the GC detector responds linearly. The correlation coefficients are all better than 0.998 .

c) Formation constants

The host/guest system (H/VOC) is characterised by a titration method. Different concentrations of host are used while the initial concentration of the VOC is constant. Assuming that 1:1 complexes are formed, the calculation of formation constant $\mathrm{K}_{\mathrm{f}}$ is developed as follows:

$$
\begin{gathered}
\mathrm{H}+\mathrm{VOC} \leftrightarrow \mathrm{H} / \mathrm{VOC} \\
\mathrm{K}_{\mathrm{f}}=[\mathrm{H} / \mathrm{VOC}] /[\mathrm{H}][\mathrm{VOC}]=[\mathrm{H} / \mathrm{VOC}] /\left([\mathrm{H}]_{T}-[\mathrm{H} / \mathrm{VOC}]\right) *\left([\mathrm{VOC}]_{T}-[\mathrm{H} / \mathrm{VOC}]\right) \\
{[\mathrm{H} / \mathrm{VOC}]=-1 / 2 \sqrt{\left.\left[1 / \mathrm{K}_{\mathrm{f}}+[\mathrm{H}]_{T}+[\mathrm{VOC}]_{T}\right)^{2}-4[\mathrm{H}]_{T}[\mathrm{VOC}]_{T}\right]}+1 / 2\left(1 / \mathrm{K}_{\mathrm{f}}+[\mathrm{H}]_{T}+[\mathrm{VOC}]_{T}\right)(3)}
\end{gathered}
$$

where $\mathrm{K}_{\mathrm{f}}$ and $\mathrm{T}$ stand for formation constant and total, respectively. For a given value of $\mathrm{K}_{\mathrm{f}},[\mathrm{H} / \mathrm{VOC}]$ is known. An algorithmic treatment developed in our laboratory is used to calculate the formation constant $\mathrm{K}_{\mathrm{f}}$ from the experimental data [14]. Only one concentration of VOC in water is needed [7].

d) Molecular modeling

All the calculations were performed with CaChe [28]. Each symmetric host structure $\left(\mathrm{CBPQT}^{4+}\right.$ and $\left.\beta-\mathrm{CD}\right)$ was first subjected to an optimization with PM3 hamiltonian. 
Partial charges for both hosts and guest were then obtained from electrostatic potentials with a single point calculation (B88-LYP energy functional with the DZVP basis sets). The docking of iodobenzene into each host was then realised by means of dummy atoms, with the MM3 force field. The distance between host and guest and the rotation of the guest inside the host were the two intermolecular variables investigated with a regular increment $\left(0.1 \AA\right.$ for distance, $5^{\circ}$ for rotation $)$, the others being implicitly submitted to Newton-Raphson optimisation. Complexation energy was defined as the difference between energy of the optimal docked structure and energy of the individual components.

\section{Conclusion}

This study explores for the first time the complexation ability of $\mathrm{CBPQT}^{4+}$ towards aromatic VOCs. The theoretical and experimental results underlined a greater capacity of $\mathrm{CBPQT}^{4+}$ to complex VOCs if compared with CDs due to a better encapsulation of the phenyl ring by $\mathrm{CBPQT}^{4+}$. Nevertheless CDs, and especially modified CDs, present a greater solubility than $\mathrm{CBPQT}^{4+}$. Further work in our laboratory will investigate the capacity of $\mathrm{CBPQT}^{4+}$ as a molecular sensor for VOCs by cyclic voltamperometry. 
References

[1] Saha, S.; Johansson, E.; Flood, A.H.; Tseng, H.-R.; Zink, J.I.; Stoddart, J.F. Chemistry - A European Journal 2005, 11(23), 6846.

[2] Cooke, G.; Garety, J.F.; Hewage, S.G.; Rabani, G.; Rotello, V.M.; Woisel, P. Chem. Comm. 2006, 39, 4119.

[3] Fourmentin, S.; Surpateanu, G.G.; Blach, P.; Landy, D.; Decock, P.; Surpateanu, G. J. Incl. Phenom. Macro. Chem. 2006, 55(3-4), 263.

[4] Surpateanu G. G., Becuwe M., Lungu N. C., Dron P. I., Fourmentin S., Landy D.; Surpateanu G. J. Photochem. Photobiol. A: Chemistry 2007, 185(2-3), 312.

[5] Castro, R.; Nixon, K. R.; Evanseck, J.D.; Kaifer, A.E., J. Org. Chem. 1996, 61(21) 7298

[6] Odell, B.; Reddington, M.V.; Slawin, A.M.Z.; Spencer R., Stoddart, J.F.; Williams, D.J., Angew. Int. Ed. Engl. 1988, 27, 1547.

[7] Fourmentin, S.; Outirite, M.; Blach, P.; Landy, D.; Ponchel, A.; Monflier, E.; Surpateanu, G. J. Haz. Mat. 2007, 141, 92.

[8] Staley, S.A.; Smith, B.D., Tet. Lett. 1996, 37(3), 283.

[9] Bria, M.; Cooke, G.; Cooper A.; Garety, J.F.; Hewage, S.G.; Nutley, M.; Rabani, G.; Woisel, P., Tet. Lett. 2007, 48, 301.

[10] Guo, Q.-X.; Luo, S.-H.; Liu, Y.-C., J. Incl. Phenom. Macro. Chem. 1998, 30, 173.

[11] Sanemasa; I.; Akamine, Y. Bull. Chem. Soc. Jpn. 1987, 60, 2059.

[12] Takuma, T.; Deguchi, T.; Sanemasa, I. Bull. Chem. Soc. Jpn. 1990, 63, 1246.

[13] Szaniszlo N., Fenyvesi E., Balla J. J. Incl. Phenom. Macro. Chem. 2005, 53, 241.

[14] Landy, D.; Fourmentin, S.; Salome, M.; Surpateanu, G. J. Incl. Phenom. Macro. Chem. 2000, 38, 187. 
[15] Saito, Y.; Yoshihara, K.; Tanamura, I.; Ueda, H.; Sato, T. Chem. Pharm. Bull. 1997, 45, 1711.

[16] Saito, Y.; Tanamura, I.; Ueda, H.; Sato. T. Chem. Pharm. Bull. 1998, 46, 1777.

[17] Saito, Y.; Tanamura, I.; Ueda, H.; Sato. T. Int. J. Cosmet. Sci. 1999, 21, 189.

[18] Saito, Y.; Misawa, K.; Hashizaki, K.; Taguchi, H.; Ogawa, N.; Ueda, H. Chem. Pharm. Bull. 2004, 52, 259.

[19] Tanamura, I.; Saito, Y.; Ueda, H.; Sato. T. Chem. Pharm. Bull. 1998, 46, 540.

[20] Wu, J.-S.; Zheng, J.-Z.; Toda, K.; Sanamasa, I. Anal. Sci. 1999, 15, 701.

[21] Misawa, K.; Saito, Y.; Hashizaki, K.; Taguchi, H.; Ogawa, N.; Ueda, H. J. Incl. Phenom. Macro. Chem. 2005, 53, 237.

[22] Lantz, A.W.; Wetterer, S.M.; Armstrong, D.W. Anal. Bioanal. Chem. 2005, 383, 160.

[23] Zhang, K.-C.; Liu, L.; Mu, T.-W.; Guo, Q.-X. Chem. Phys. Lett. 2001, 333, 195.

[24] Zhang, K.-C.; Liu, L.; Mu, T.-W.; Guo, Q.-X. J. Incl. Phenom. Macro. Chem. 2001, 40, 189.

[25] Kolb, B. J. Chromatogr. A 1999, 842, 163.

[26] Snow, N.H.; Slack, G.C. Trends Anal. Chem. 2002, 21, 608.

[27] Kolb, B.; Ettre, L.S. Static Headspace-Gas Chromatography Theory and Practice, Wiley-VCH, New York, USA, 1997.

[28] CAChe, Work System, 6.01, 2003. 


\section{$\underline{\text { Figure Captions }}$}

Figure 1: Chemical structure of (1) cyclobis(paraquat- $p$-phenylene) tetrachloride salt and (2) $\alpha-C D$ : if $n=1$ and $R=H$; $\beta-C D$ : if $n=2$ and $R=H$ : RAMEB; if $n=2$ and $R=H$ or $\mathrm{CH}_{3}$ (1.8 OH groups modified per glucopyranose unit).

Figure 2: Representation of the variation of the chromatogram of toluene $10 \mathrm{ppm}$ (a) with various concentrations of $\mathrm{CBPQT}^{4+}: 0.03 \mathrm{mM}(\mathrm{b}), 0.1 \mathrm{mM}(\mathrm{c}), 0.2 \mathrm{mM}$ (d) and $0.3 \mathrm{mM}(\mathrm{e})$

Figure 3: Representation of the experimental point $(\diamond)$ obtained for iodobenzene and $\mathrm{CBPQT}^{4+}$ compare with theoretical titration curve (- -) for a 1:1 complex $\left(\mathrm{K}_{\mathrm{f}}=9459 \mathrm{M}^{-1}\right)$ with the algorithmic treatment.

Figure 4: Variation of $\log \mathrm{K}_{\mathrm{f}}$ in function of molar refractivity (MR) of the substituent for $\beta-\mathrm{CD}(\mathbf{\Delta})$ and $\mathrm{CBPQT}^{4+}(\bullet)$.

Figure 5: Optimized MM3 structures for inclusion of iodobenzene in $\mathrm{CBPQT}^{4+}(1)$, and in $\beta-\mathrm{CD}(2)$. 


\section{$\underline{\text { Table Captions }}$}

Table 1: Formation constants $\left(\mathrm{M}^{-1}\right)$ obtained at $30^{\circ} \mathrm{C}$ for the different VOCs with $\mathrm{CBPQT}^{4+}, \alpha-\mathrm{CD}, \beta-\mathrm{CD}$ and RAMEB 

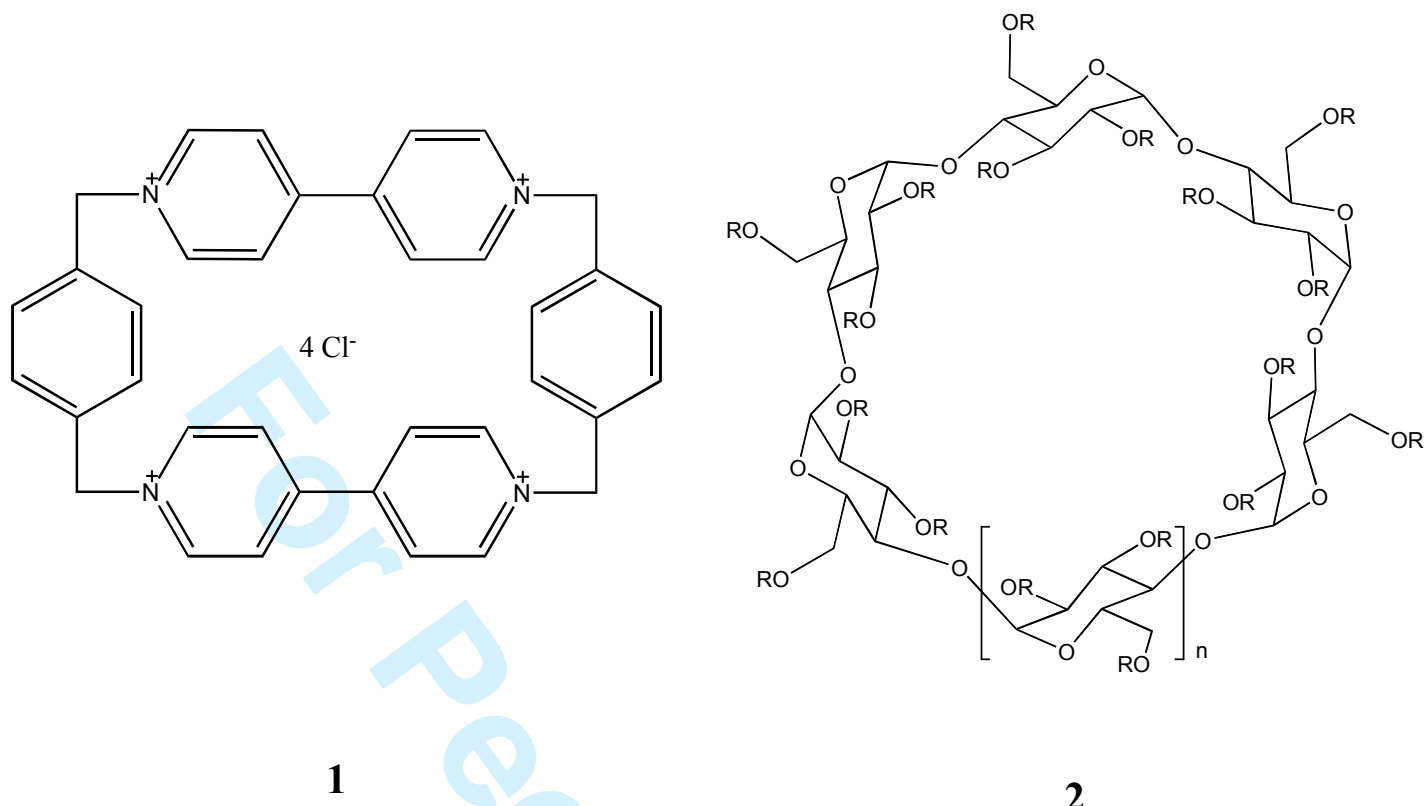

Figure 1: Chemical structure of (1) cyclobis(paraquat- $p$-phenylene) tetrachloride salt and (2) $\alpha-C D$ : if $n=1$ and $R=H$; $\beta-C D$ : if $n=2$ and $R=H$ : RAMEB; if $n=2$ and $R=H$ or $\mathrm{CH}_{3}$ (1.8 OH groups modified per glucopyranose unit). 


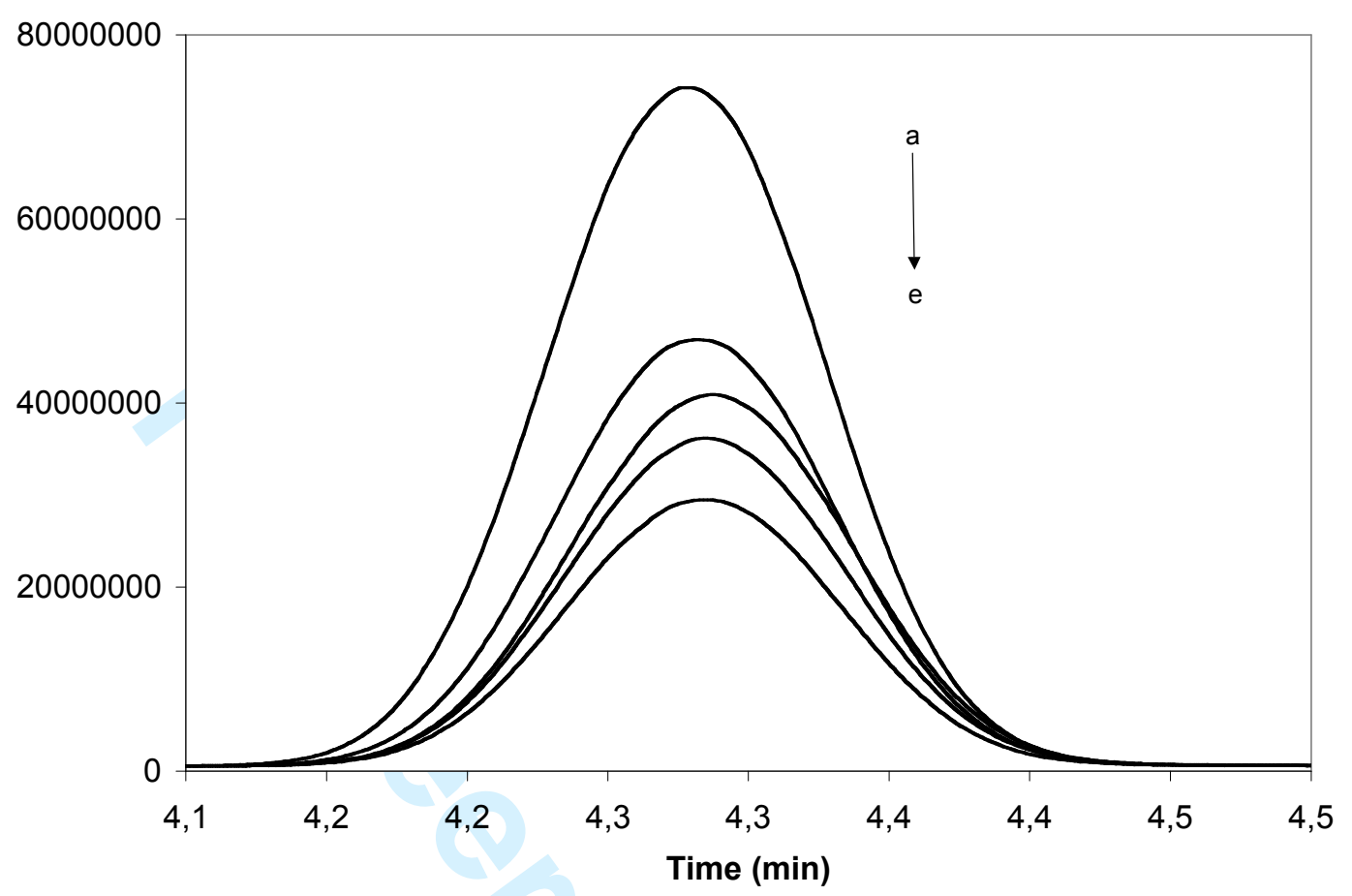

Figure 2: Representation of the variation of the chromatogram of toluene $10 \mathrm{ppm}$ (a) with various concentrations of $\mathrm{CBPQT}^{4+}: 0.03 \mathrm{mM}$ (b), $0.1 \mathrm{mM}$ (c), $0.2 \mathrm{mM}$ (d) and $0.3 \mathrm{mM}(\mathrm{e})$ 


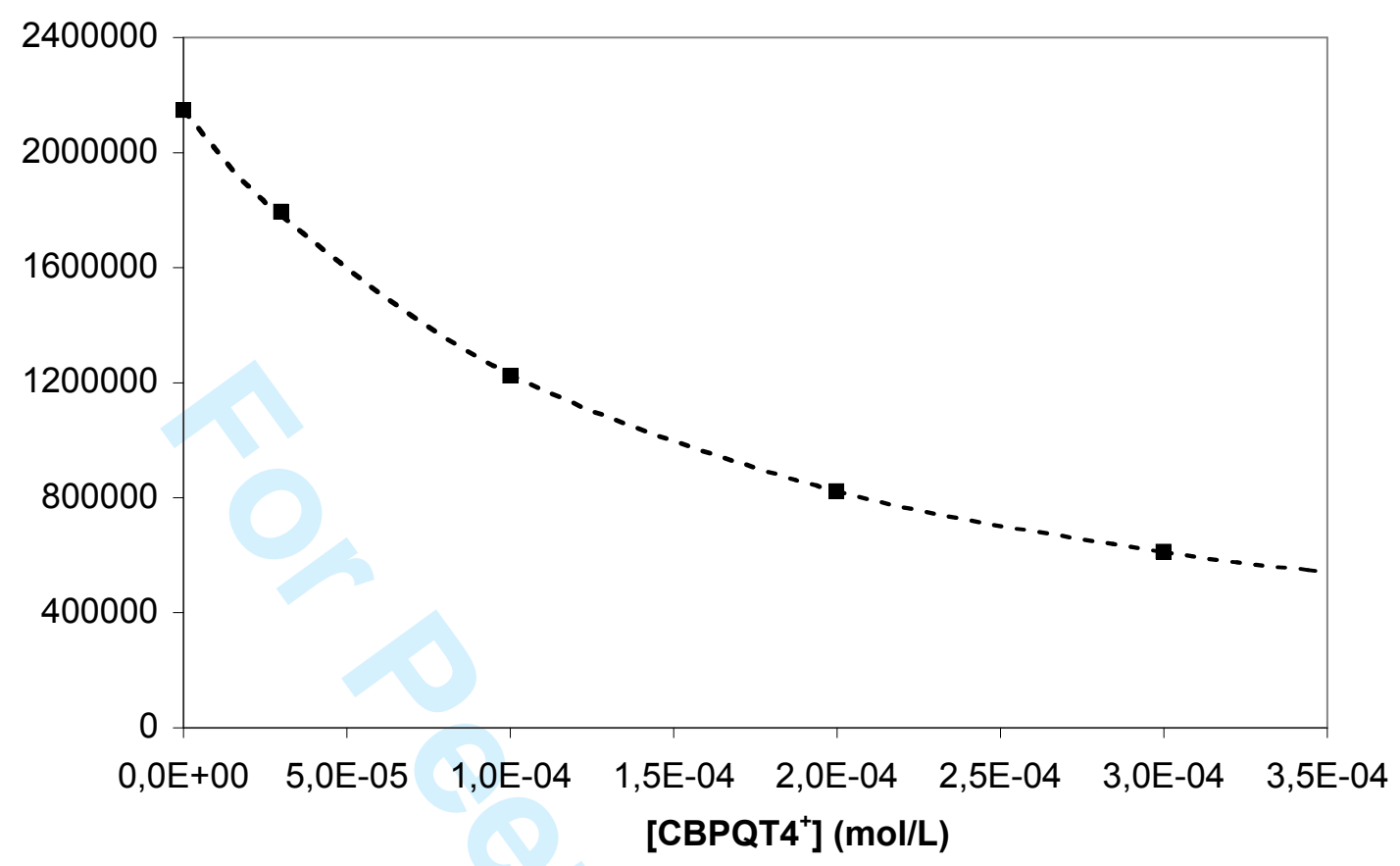

Figure 3: Representation of the experimental point $(\diamond)$ obtained for iodobenzene and $\mathrm{CBPQT}^{4+}$ compare with theoretical titration curve (- -) for a 1:1 complex $\left(\mathrm{K}_{\mathrm{f}}=9459 \mathrm{M}^{-1}\right)$ with the algorithmic treatment. 


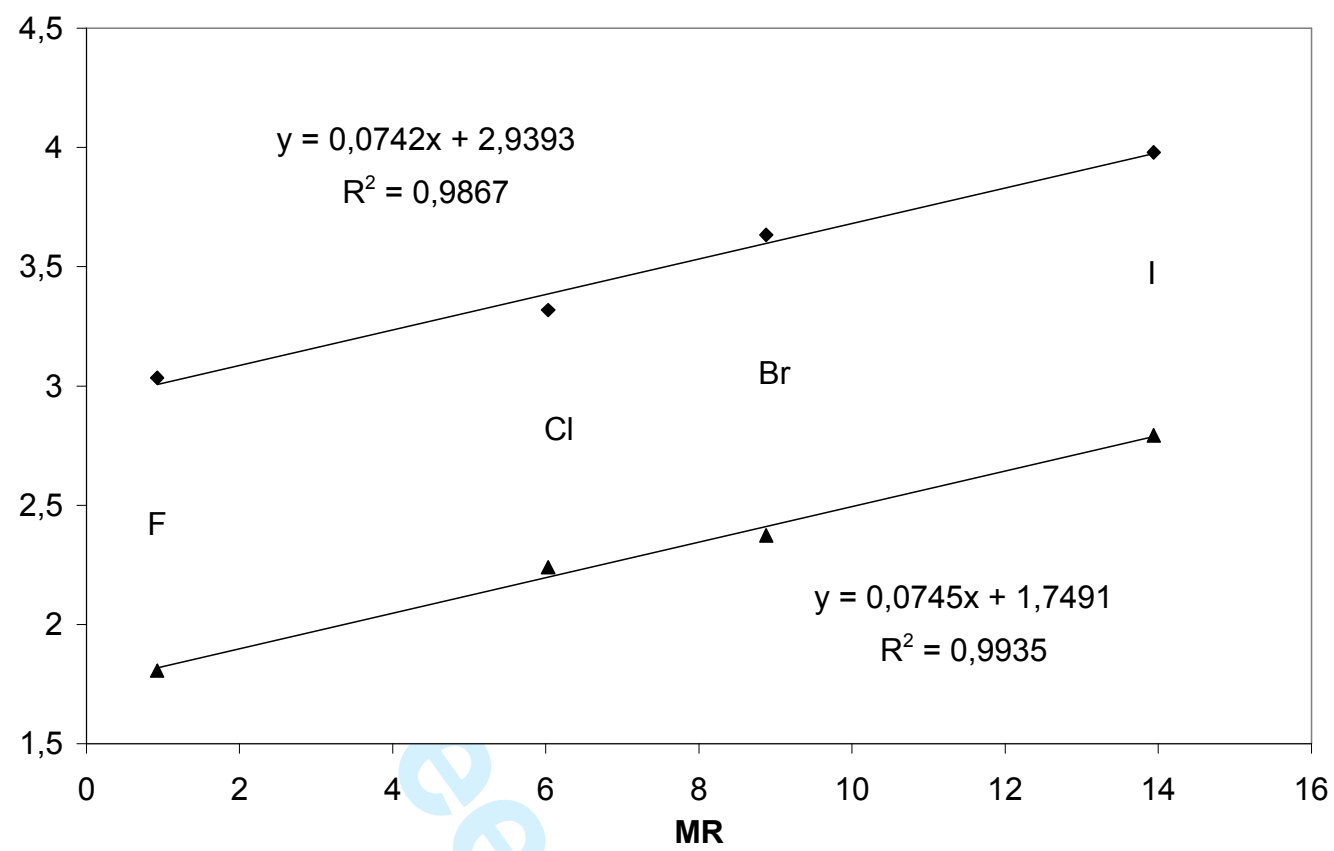

Figure 4: Variation of $\log \mathrm{K}_{\mathrm{f}}$ in function of molar refractivity (MR) of the substituent for $\beta-\mathrm{CD}(\mathbf{\Delta})$ and $\mathrm{CBPQT}^{4+}(\bullet)$. 

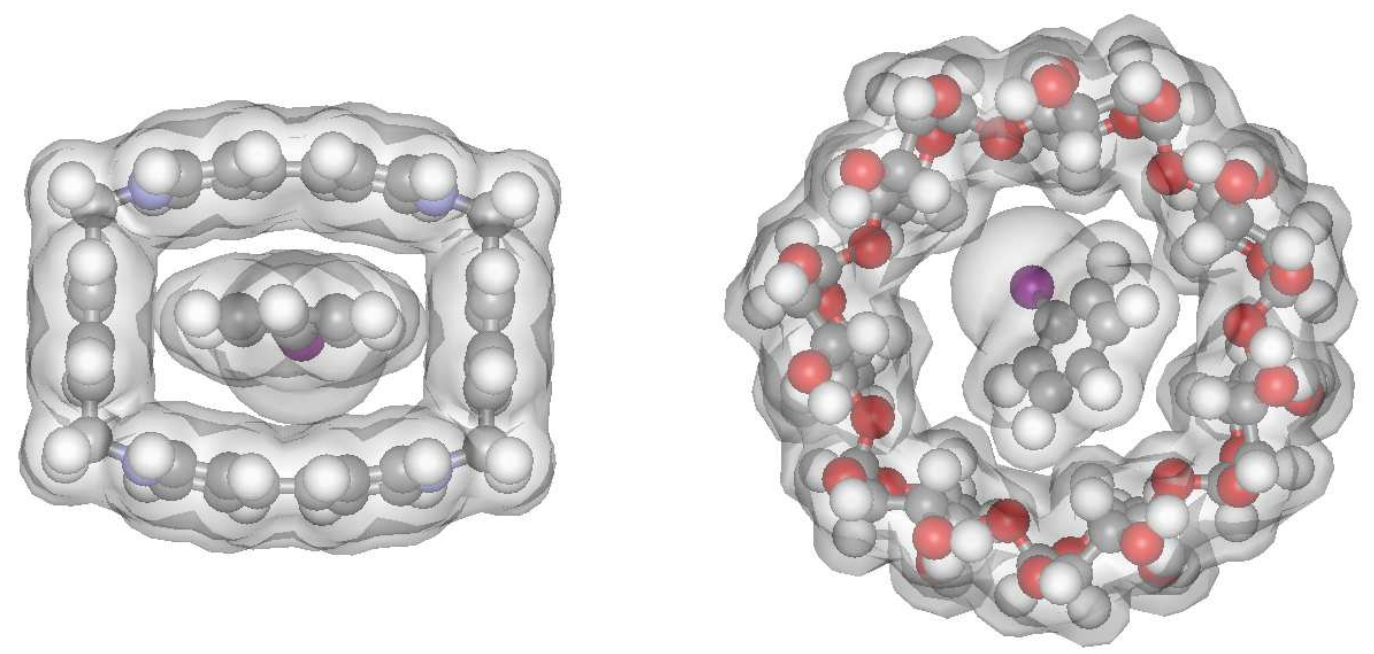

1

2

Figure 5: Optimized MM3 structures for inclusion of iodobenzene in $\mathrm{CBPQT}^{4+}(\mathbf{1})$, and in $\beta-C D(2)$. 


\begin{tabular}{lcccc}
\hline & CBPQT $^{4+}$ & $\alpha-C D$ & $\beta-C D$ & RAMEB \\
Toluene & 3872 & $38\left(29^{\mathrm{a}}\right)$ & $\begin{array}{c}142\left(140^{\mathrm{b}}-\right. \\
\left.172^{\mathrm{a}}\right)\end{array}$ & $171\left(144^{\mathrm{a}}\right)$ \\
Fluorobenzene & 1083 & $31\left(34^{\mathrm{c}}\right)$ & $64\left(70^{\mathrm{c}}\right)$ & 90 \\
Chlorobenzene & 2300 & $128\left(100^{\mathrm{c}}\right)$ & $174\left(160^{\mathrm{c}}\right)$ & 157 \\
Bromobenzene & 4312 & $333\left(51^{\mathrm{c}}\right)$ & $237\left(310^{\mathrm{c}}\right)$ & 244 \\
& & & \\
Iodobenzene & 9459 & $917\left(1100^{\mathrm{c}}\right)$ & $622\left(800^{\mathrm{c}}\right)$ & 785 \\
\hline In bracket literature data; See references: ${ }^{\mathrm{a}}[13]^{\mathrm{b}}[11],{ }^{\mathrm{c}}[12]$ &
\end{tabular}

Table 1: Formation constants $\left(\mathrm{M}^{-1}\right)$ obtained at $30^{\circ} \mathrm{C}$ for the different VOCs with $\mathrm{CBPQT}^{4+}, \alpha-\mathrm{CD}, \beta-\mathrm{CD}$ and RAMEB 


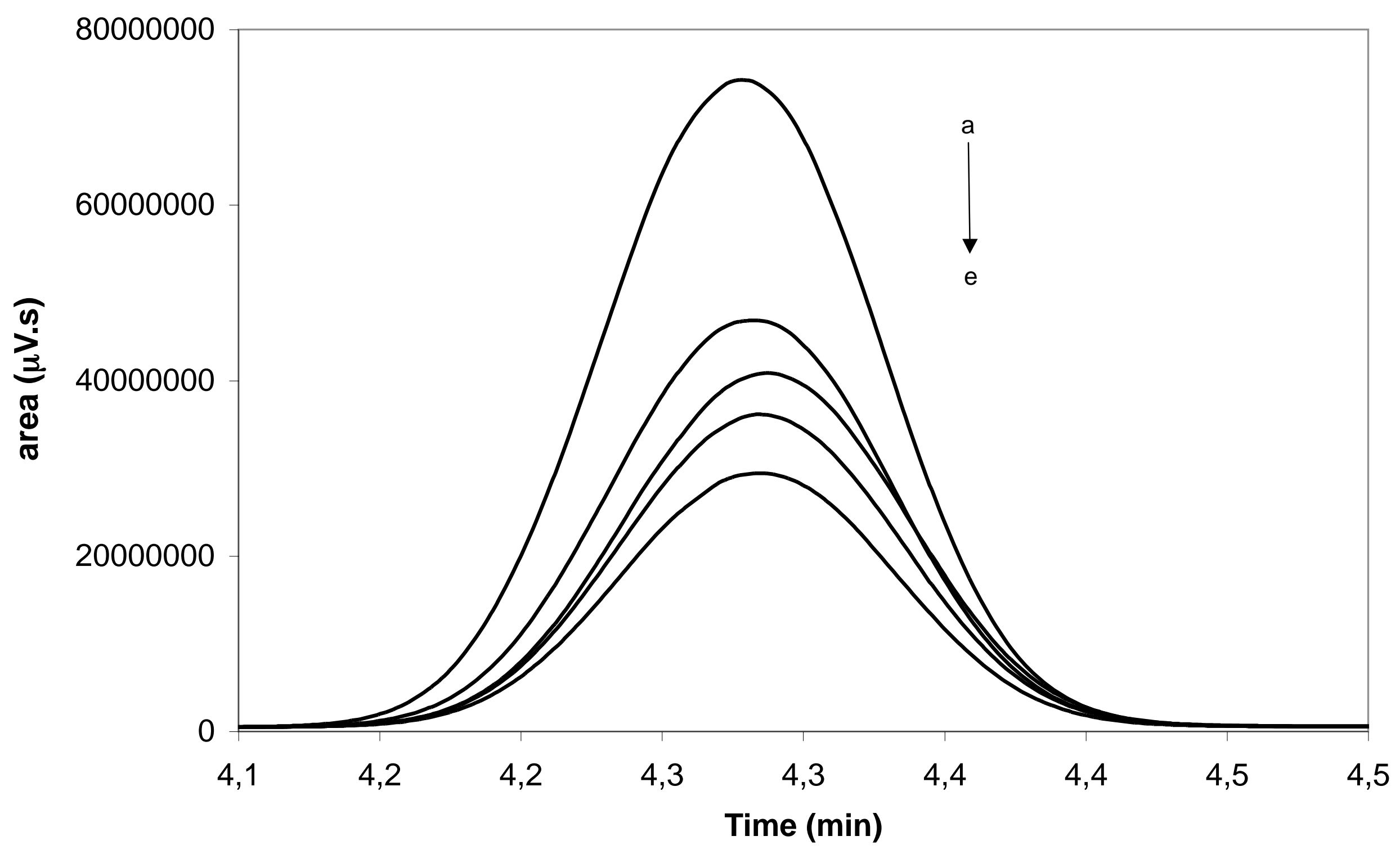

URL: http:/mc.manuscriptcentral.com/tandf/gsch Email: suprachem@mail.cm.utexas.edu 


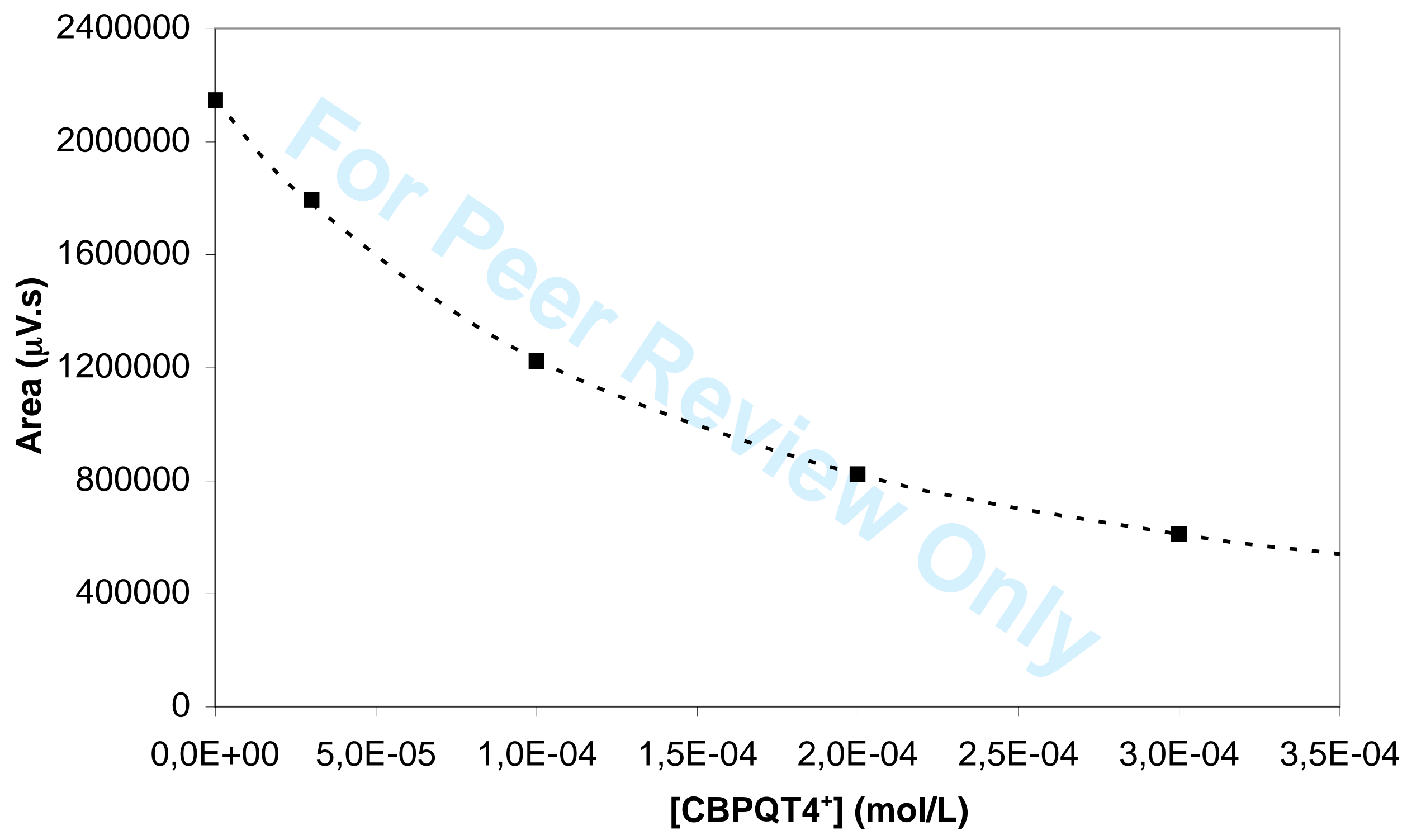

URL: http:/mc.manuscriptcentral.com/tandf/gsch Email: suprachem@mail.cm.utexas.edu 


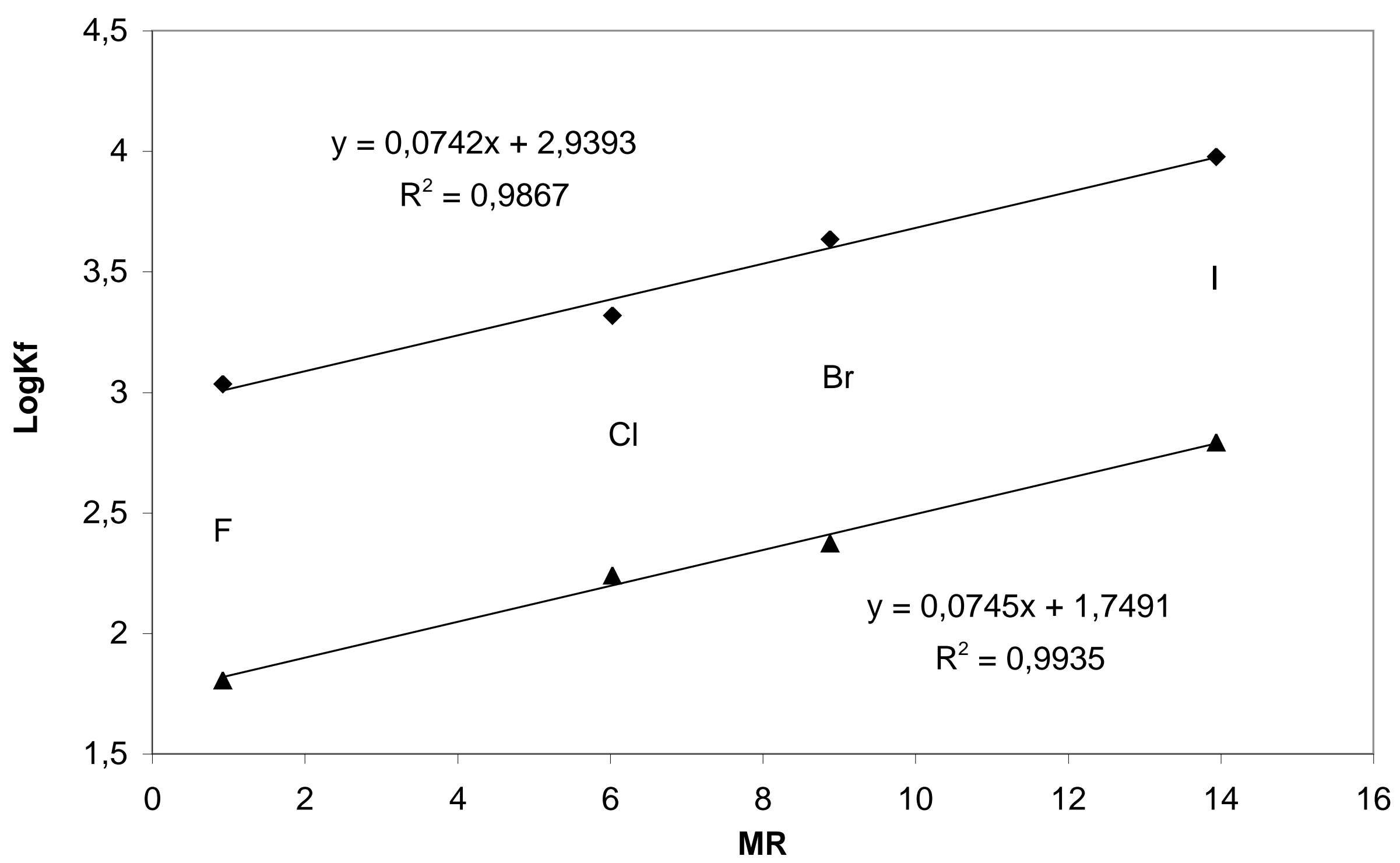

URL: http:/mc.manuscriptcentral.com/tandf/gsch Email: suprachem@mail.cm.utexas.edu 


\section{Supramolecular Chemistry}

Page 22 of 22

1

2

3

4

5

6

7

8

9

10

11 U⿳亠丷厂巾2
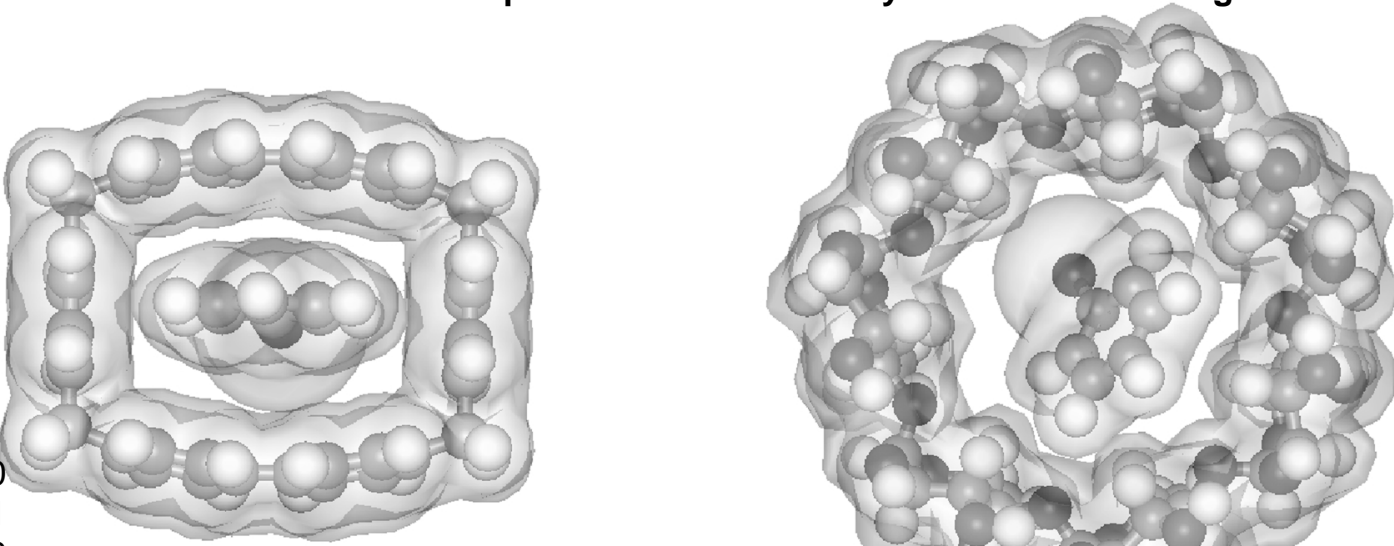
13

14

15 